\title{
Production Capacity Planning with Market Share Expansion under Different Procurement Strategies
}

Sidi Wu* and Hisashi Onari

Department of Industrial and Management Systems Engineering, Waseda University, Tokyo, Japan

\begin{abstract}
Market share expansion strategy is usually considered by the manufacturers who intend to achieve lower production cost to extend the surviving period in mature markets where intense price competition occurs frequently. This study will discuss one manufacturer who is producing mature stage products and supplying them to product market to serve the end users. In order to produce the products, it is necessary for the manufacturer to procure the key components of the products from the component market which is on its fast-growing stage with high price fluctuation. Spot procurement and SC procurement are to be compared to find out which is a better strategy to support the manufacturer in the decision-making of production capacity. Profit rate, deficit rate and market share rate are considered as the valuation index in this study.
\end{abstract}

Keywords: Supply chain; Uncertainty; Production capacity planning; Component procurement; Market share expansion; Contract

\section{Introduction}

This paper focuses on the manufacturers who are producing the mature stage products and supplying them to the product market. In order to finish products producing, it is necessary for them to do procurement of key components from the component market. Market share expansion strategy is usually considered by these manufacturers in order to get lower production cost to extend the surviving period in such mature market with intense price competition. To expand market share, it means, manufacturers should plan more production capacity. Price increasing and short supply of components makes the manufacturers worry about low profit achievement and over investment. Especially, while the components are on their fastgrowing stage, high price fluctuation and high supply uncertainty make components procurement risk more serious. For example, like camera manufacturers in Japan, they are under such severe environments. Camera is a mature product in Japan, an image sensor can be considered as the key component of a camera, the sell price of a camera decided by the price of the sensor. Especially, purchasing cost of a high-class sensor occupies a large proportion of the sell price of a high-class camera (Figure 1). Image sensors are also used to produce fast-growing products such as surveillance camera, security systems for automobile and so on.

This paper will discuss the component procurement strategies while manufacturers taking market share expansion strategy. Two kinds of procurement strategies of manufacturers were taken into considered. The first one is that manufacturers do procurement from component suppliers with spot contracts. Manufacturers and component suppliers determine the trading volume of components with the market price by negotiation after production capacity planning. They need to decide

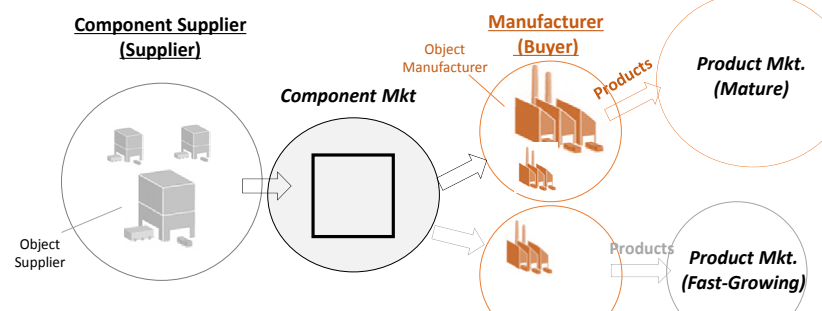

Figure 1: The object market and players. the production capacity with demand forecasting of the component market and product market and do decision making by themselves. The second one is that manufacturers do procurement from component suppliers with supply chain contracts. Manufacturers and component suppliers should determine the trading volume of components and trading price by negotiation before investment and production capacity planning. Actually, effectiveness of component procurement with both two strategies is verified on previous studies, and they have already widely used by manufacturers in practice. But in order to know the difference between the two strategies by quantification, in this paper, the independent decision making model with spot contract only and collaborate decision making model with supply chain contract were designed.

The purpose of this paper is to reveal the effectiveness of supply chain contract procurement of components while manufacturers planning the production capacity with market-share expansion strategy with the key component on its fast-growing stage. The evaluation items are considered as profit rate and market share of the manufacturer. Furthermore, the effectiveness range such as market condition and characteristics of players are also to be shown in the last part of this paper.

\section{Literature Review}

With considering of the uncertainty of trading price in spot market, the decision-making model for each collaboration level of the supplier and the buyer was proposed with using a long-term supply chain contract and a short term sales contract simultaneously. They considered a base stock policy and compared it to single sourcing options, examined the joint effect of demand and spot price uncertainty [1]. Effectiveness of the proposal was proved with comparing with the supply chain total profit. In high-tech industry, it is difficult for component suppliers to expand their production capacities with

*Corresponding author: Sidi Wu, Department of Industrial and Management Systems Engineering, Waseda University, Tokyo, Japan, Tel: (+81) 3-5286-3192; E-mail: sidiwu@aoni.waseda.jp

Received May 12, 2016; Accepted May 24, 2016; Published May 25, 2016

Citation: Wu S, Onari H (2016) Production Capacity Planning with Market Share Expansion under Different Procurement Strategies. Int J Econ Manag Sci 5: 345 doi:10.4172/2162-6359.1000345

Copyright: @ 2016 Wu S, et al. This is an open-access article distributed under the terms of the Creative Commons Attribution License, which permits unrestricted use, distribution, and reproduction in any medium, provided the original author and source are credited. 
constraints of investment capital. As a result, opportunity loss of whole supply chains occur due to buyers cannot get enough volume of components to meet the needs of product demand. A contract called deductible reservation was proposed. Decision making models of players with the contract was designed. Deductible reservation contract was compared with take-or-pay contract by supply chain total profit and profit of each player. The proposed deductible reservation contract was proved as the effectiveness one between the two contracts [2]. The two studies discussed the effectiveness of long-term supply chain contract while doing decision-making of production capacity planning under uncertain market environment.

The effectiveness of contract preconditions was also discussed in many previous studies. Pay-to-delay contract set the trading volume and price to three levels, players will set their production capacity with considering of the preconditions about the level of volume and price [3]. Capacity reservation contracts between a supplier and multiple buyers originated from a project completed at a major telecommunications component manufacturer in US were discussed. Reservation fees which decided by the supplier can be deducted from the purchase price paid at delivery. Contracts between a supplier and a manufacturer involving a fixed trading price (contract price) for further purchases by the manufacturer, and a spot price determined by component market after the demand is realized in the future was discussed. Preconditions make the contract more flexible, and supplier and buyer can decide a fixed price of components by negotiation in the first step, trading volume can be adjusted in a decided range in the second step [4]. Procurement strategies combining spot market purchases with purchases based on a long-term supply chain contract. A three-parameter optimal policy was derived.

Many studies proposed a lot of new contract methods and preconditions of contract to hedge supply chain risks while players planning new production capacity, but few studies concerned the difference of procurement strategies. Uncertainties were taken into consideration in many previous studies, but the difference of uncertainties in mature market and fast growing market has not been revealed before [5-7].

\section{Market Model}

In this section, the difference of market features and uncertainties between mature product market and fast growing product market is to be discussed.

\section{Market features}

Figure 2 shows the demand transition of mature product market. There is almost no change of the average demand in such market, but

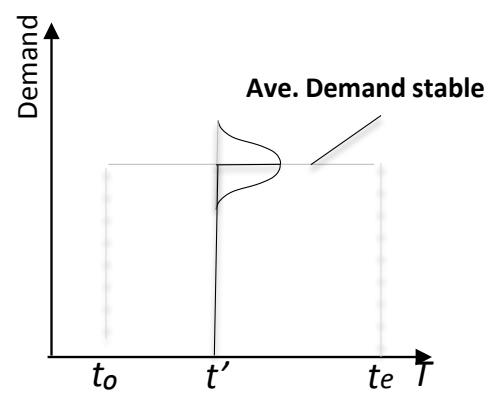

Figure 2: Demand transition of mature mkt. demand variation occurs in each period due to the replacement needs. Figure 3 shows the price transition of mature product market. With intense price competition, market price decline occurs significantly. Variation of price also occurs in each period, because of supplydemand unbalance [8-12].

Figure 4 shows the demand transition of fast-growing product market. Average demand grows by time. Demand variation also occurs in each period. Figure 5 shows the price transition of fast-growing product market. Because of demand growing is faster than supply growing, the market price becomes high. Variation of price also occurs in each period because of supply-demand unbalance [13-15].

\section{Market uncertainties}

There are two kinds of uncertainties are taken into consideration in this paper. Figures 6-9 show the uncertainties in mature product market and fast-growing product market.

The first one is the center price, and the second one is the variation of price range. Market center price is a price decided by the leading

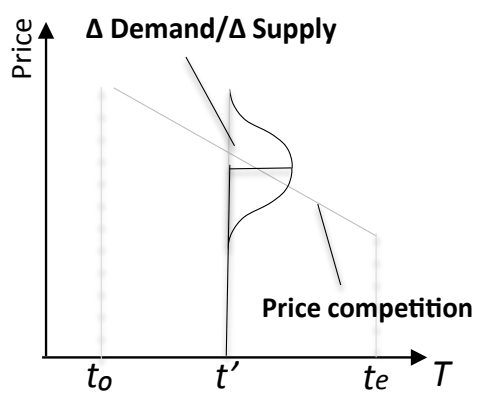

Figure 3: Price transition of mature mkt.

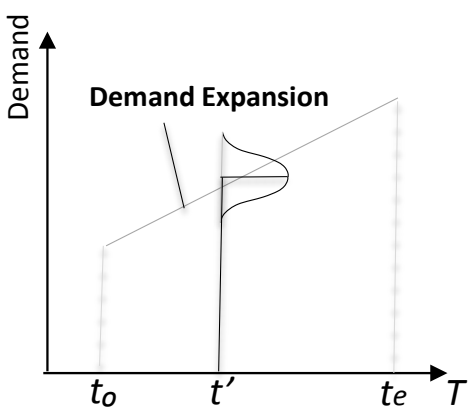

Figure 4: Demand transition of fast-growing mkt.

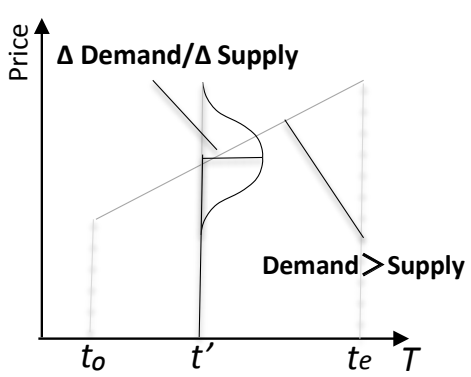

Figure 5: Price transition of fast-growing mkt. 


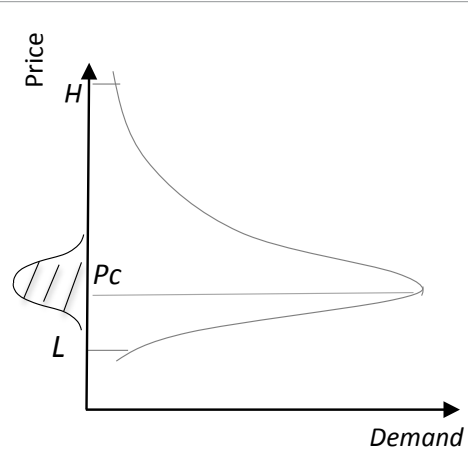

Figure 6: Center price in mature mkt.

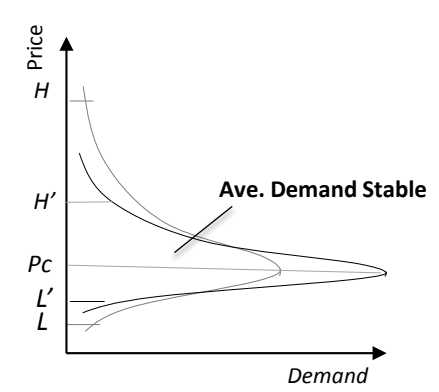

Figure 7: Price range variation in mature mkt.

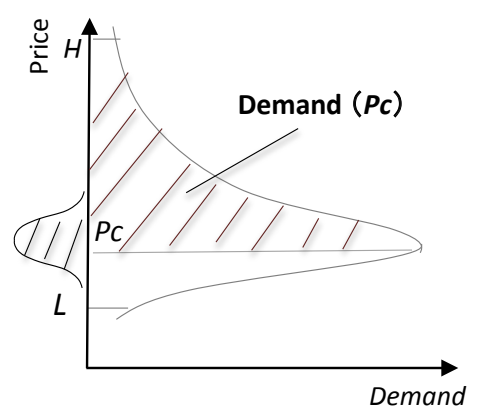

Figure 8: Center price in fast-growing mkt.

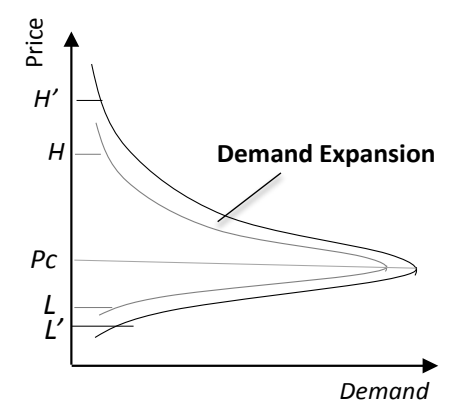

Figure 9: Price range variation in fast-growing mkt.

manufacturer in a market. Figure 6 shows the uncertainty of center price in a mature product market. Figure 7 shows the uncertainty of variation of price range in a mature product market. The range of $(L, H)$ changes with the fixed average demand. Figure 8 shows the uncertainty of center price in a fast-growing product market. The shadow area shows the total demand with center price which follows a normal distribution. Figure 9 shows the uncertainty of variation of price range in a fast-growing product market. The range of $(\mathrm{L}, \mathrm{H})$ changes due to the area of distribution changing with demand expansion. Both max market price $\mathrm{H}$ and min market price $\mathrm{L}$ follow the normal distributions. This paper a triangle is used to do the calculation instead of demand distribution $[16,17]$.

\section{Decision Making Model}

In this section, the decision making model of production capacity planning with both spot contract and supply chain contract is to be discussed.

\section{Production capacity planning with spot contract}

Spot contract is a short term contract that a manufacturer does procurement of components with market price and the trading volume is decided by a component supplier and a manufacturer with negotiation. Usually, spot contract is to be connected by players after production capacity planning and investment. In this paper, contract span, contract cycle and contract bucket are set as 3 month.

With the estimated demand distribution of product market and supply distribution of component market, manufacturers do production capacity planning with expected profit and expected loss calculation. Total value of expected profit and expected loss are considered as the evaluation value. The expected loss is considered as the following two cases. (1) Demand is less than the expected supply amount of products. (2) The amount of component is less than the actual demand. Manufacturers should find out the production capacity $\mathrm{Q}$ with the max evaluation value. Figure 10 shows the estimated demand price distribution of product market and Figure 10 shows center price.

The range of $\mathrm{Q}$ set as $\left(\mathrm{Q}_{\min }, \mathrm{Q}_{\max }\right) \cdot \mathrm{Q}_{\min }$ can be calculated with the current share rate and total demand of market. $\mathrm{Q}_{\max }$ can be calculated with the desired share rate and total demand of market. If the actual center price of product were lower than the estimated one, like $\mathrm{P}_{c^{\prime}}$ in Figure 11, expected share rate becomes low as well as the profit also becomes low. Otherwise, like $\mathrm{P}_{\mathrm{c}^{\prime \prime}}$ in Figure 11, expected share can be achieved. Profit also becomes higher than the expected one.

Relation between demand and price can be showed with formula 1 and formula 2 . Angle $\theta$ is set as a parameter to show the price elasticity of the market.

$$
\mathrm{D}=1 / 2\left[\tan \theta \cdot\left(\mathrm{P}_{\max }-\mathrm{P}^{\prime}\right)\right]\left(\mathrm{P}_{\max }-\mathrm{P}^{\prime}\right)\left(\mathrm{P}^{\prime} \geq \mathrm{P}_{\mathrm{c}}\right)
$$

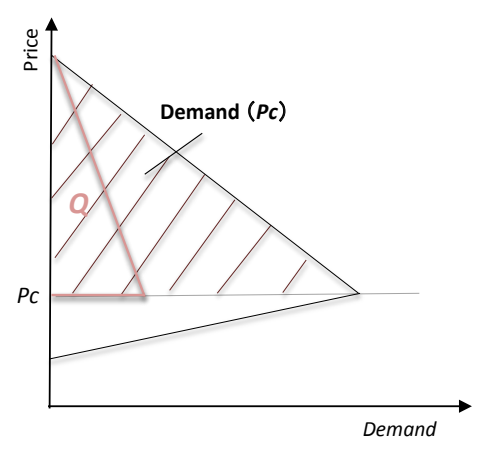

Figure 10: Demand price distribution. 


$$
\begin{aligned}
& D=\left\{D_{\max }-\frac{1}{2}\left[\tan \theta \cdot\left(\mathrm{P}_{\max }-\mathrm{P}_{c}\right)\right]\left(\mathrm{P}_{\max }-\mathrm{P}_{c}\right)\right\}-\frac{1}{2}\left(\mathrm{P}^{\prime}-\mathrm{P}_{\min }\right)\left[\frac{2 D_{\max }\left(\mathrm{P}_{c}-\mathrm{P}_{\min }\right)}{\left(\mathrm{P}_{\max }-\mathrm{P}_{\min }\right)}\right] \\
& +\frac{1}{2}\left[\tan \theta \cdot\left(\mathrm{P}_{\max }-\mathrm{P}_{c}\right)\right]\left(\mathrm{P}_{\max }-\mathrm{P}^{\prime}\right)\left(\mathrm{P}^{\prime}<\mathrm{P}_{c}\right) \\
& \mathrm{P}_{\max }: \text { Max price of market } \\
& \mathrm{P}_{\min }: \text { Min price of market } \\
& \mathrm{P}^{\prime}: \text { The actual price in the future } \\
& \mathrm{P}_{c}: \text { Center price } \\
& \mathrm{D}_{\max }: \text { Average total demand of market }
\end{aligned}
$$

Figure 12 shows the relation between supply and price of component market. Figure 13 shows the price rise risk in the component market which occurs by short supply to this product market.

With considering of the risk and return in product market and

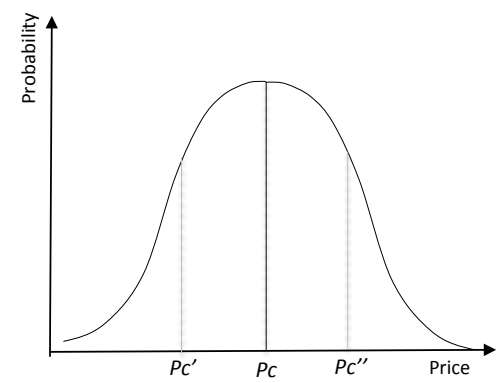

Figure 11: Center price.

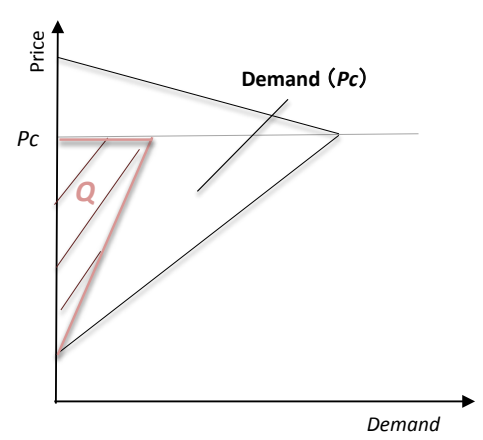

Figure 12: Supply price distribution.

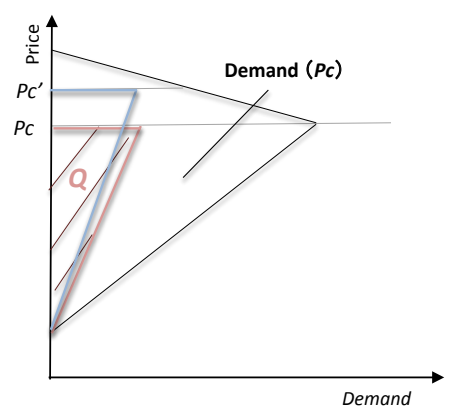

Figure 13: Price rise with short supply. component market. Expected profit and expected loss and value can be calculated with the formulas below:

$$
\begin{aligned}
& \text { Expected profit }=q P_{p c}^{\prime}-Q P_{c c}^{\prime}-\text { Cost }_{m} \\
& \text { Value }=\text { Expected profit }+ \text { Expected loss } \\
& \mathrm{Q} \text { : Candidate production capacity } \mathrm{Q}=\mathrm{Q}_{0}(1+\mathrm{r}) \\
& \mathrm{Q}_{0} \text { : Current production capacity } \\
& \text { r: Desired share rate for next term } \\
& \text { q: Actual sell amount, set it as } \mathrm{q}=1 / 2\left(\mathrm{Q}-\mathrm{Q}_{0}\right) \\
& \mathrm{P}_{\mathrm{pc}} \text { ': Center price of product market } \\
& \mathrm{P}_{\mathrm{cc}} \text { : } \text { : Center price of component market } \\
& \mathrm{P}_{\text {pmin }} \text { : Minimum price of product market } \\
& \mathrm{P}_{\text {cmax }} \text { : Maximize price of component market } \\
& \text { Cost }_{\mathrm{m}} \text { : Production cost of manufacturer }
\end{aligned}
$$$$
\text { Expected loss }=\Sigma_{i=1}^{P_{p c}} P_{p \min }\left[Q P_{p c}^{\prime}-q P_{p i}\right] P\left(P_{p i}\right)+\Sigma_{i=1}^{P_{c c}-P_{c \max }}\left[q P_{c i}-Q P_{c c}^{\prime}\right] P\left(P_{c i}\right)
$$

After the calculation, the manufacturer will set the production capacity for next term as $\mathrm{Q}$ with the best value. After production capacity preparation, the manufacturer will make the order $\mathrm{Q}$ to the supplier.

\section{Production capacity planning with SC contract}

Supply chain contract is a long term contract that a component supplier and a manufacturer decide the trading volume and trading price of components at an early time before production capacity planning and investment by negotiation. In this paper, contract span, contract cycle and contract bucket are set as 48 month, 12 month, and 3 month.

In this paper, supply chain contract parameters are set as max trading volume, min trading volume and the trading (contract) price. The manufacturer decide the min purchasing volume, the component supplier decide the max supply volume. The trading price is to be decided by the two players with negotiation.

The min purchasing volume can be considered as the current production volume $\mathrm{Q}_{0}$. So the manufacturer set the min purchasing volume as $\mathrm{Q}_{0}$. Besides $\mathrm{Q}_{0}$, he also has to inform the supplier the expected supply volume $\mathrm{Q}$ of product with the desired market share rate. After achieving $\mathrm{Q}$ and $\mathrm{Q}_{0}$, with estimated distribution of demand and price, the component supplier will decide the max trading volume.

Max trading volume and min trading volume can be calculated with the formulas as below:

$$
\begin{aligned}
& \mathrm{Q}_{\min }=\mathrm{Q}_{0} \\
& \mathrm{Q}_{\text {max }}=\left[(1-\mathrm{R}) \mathrm{Q}_{\text {min }} \mathrm{P}_{c c}{ }^{\prime}\right] / \text { Cost }_{\mathrm{s}}
\end{aligned}
$$

R: Expected profit rate of component supplier

\section{Cost : Production cost of component supplier}

With the max trading volume and the min trading volume, supplier and manufacturer will decide the trading price with negotiation. It is necessary for the two players to do profit and loss calculation during the negotiation. In this paper, to simplify the negotiation process, middle price of expected price of the two players are considered as the trading price. 
With considering of the risk and return in product market and contract parameters. Expected profit and expected loss and value can be calculated with the formulas below:

$$
\begin{aligned}
& \text { Expected profit }=q P_{p c}^{\prime}-Q p-\text { Cost }_{m} \\
& \text { Expected loss }=\Sigma_{i=1}^{P_{p c}-P_{p \min }}\left[Q P_{p c}^{\prime}-q P_{p i}\right] P\left(P_{p i}\right)
\end{aligned}
$$

Value=Expected profit + Expected loss (10)

Q: Candidate production capacity $\mathrm{Q} \in\left(\mathrm{Q}_{\min }, \mathrm{Q}_{\max }\right)$

After the calculation, the manufacturer will set the production capacity for next term as $\mathrm{Q}$ with the best value. So, the range of order is $\left(\mathrm{Q}_{\text {min }}, \mathrm{Q}\right)$.

\section{Experiment}

In this section, experiments and results are to be discussed.

\section{Experiment instructions}

Firstly, profit rate while the manufacturer taking share up strategy in the mature product market were confirmed. Secondly, spot procurement and supply chain procurement with share rate to confirm the effectiveness of supply chain procurement in this kind of situation were compared. Trading period were set as 4 terms (48 month).

\section{Results}

In the following section shows the result of simulation.

Figure 14 shows the profit achievement of the manufacturer with spot procurement and supply chain procurement. Profit becomes low in accordance with the time. But, in each term, profit achievement with supply chain procurement is more than spot procurement. There are two reasons. The first one is risk hedging during the decision-making of production planning almost occurs in the first half of the whole period. The second one is the problem of balance carried forward almost occurs in the second half of the period.

It is difficult for the manufacturer to expand share sustainably when deficit occurs due to the problem of balance carried forward. So, the manufacturer is considered that he could not get survived while deficit occurs. During the experiment, probability of deficit with spot procurement is much higher than supply chain procurement. Figure 15 shows the comparison about the rate of failure with these two procurement methods. Once budget deficit occurs, share up expansion failure occurs. In most cases, deficit occurs from term 3 and term 4 . In term 3 , rate of failure is much lower by decision-making with supply chain procurement.
Spot
ש Supply Chain

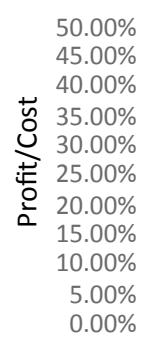

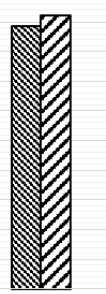

$\mathrm{T} 1$

Figure 14: Profit rate comparison.
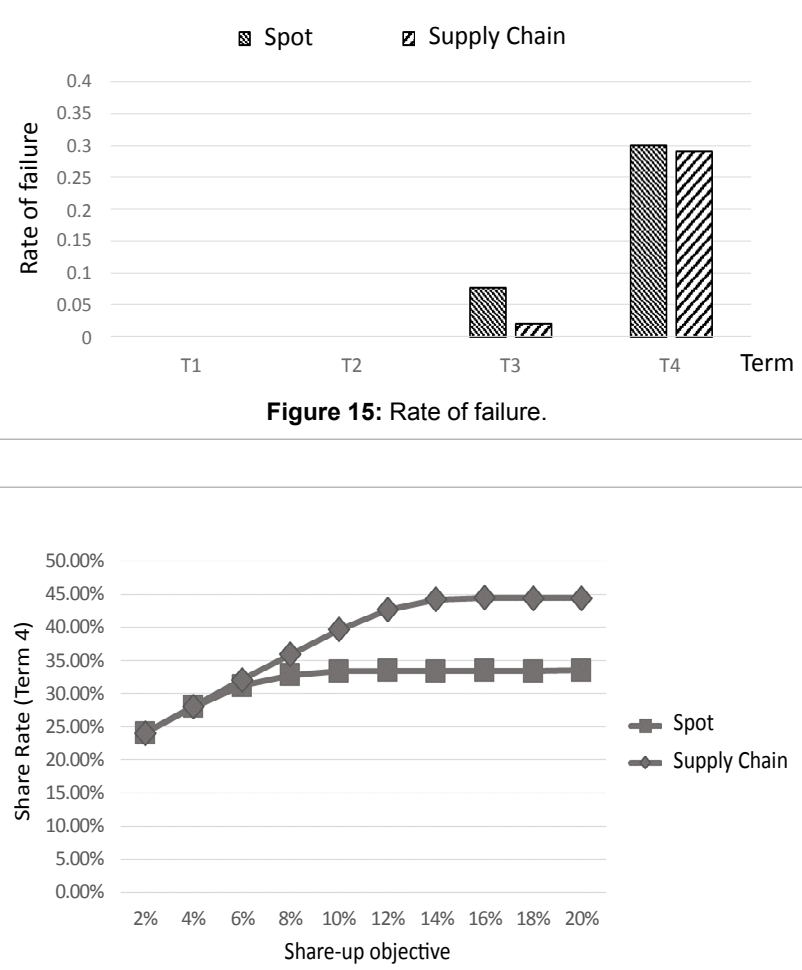

Figure 16: Share rate comparison (Term End).

Figure 16 shows the share rate with these two procurement methods in each trading term. It is difficult for spot procurement to expand the desired share rate of manufacturer. Especially, with the price competition of product market becoming heavy, the share rate may become lower than the initial value. The desired share rate can be considered as a characteristic of the manufacturer. An optimistic manufacturer may set a higher desired share rate and do production planning positively. So, it is better for these manufacturers to purchase components with supply chain contract in a high uncertainty market.

\section{Discussion and Conclusions}

In this paper, uncertainties in mature market and fast growing market were defined. Also, the model of short-term spot contract and long-term supply chain contract were created. After that, the manufacturer's decision-making models of production capacity planning with both component procurement methods were designed. Do procurement of key components in a fast growing market with high uncertainties and supply the finish product to a mature market with heavy price competition is very difficult to manufacturers. In this kind of situation, in order to get a long survival period in the product market, it is better for the manufacturer to do investment to expand the market share with connecting a long-term supply chain contract with a fixed supplier.

With the market model and the decision making model, evaluation items of profit achievement, failure rate and share rate expansion were taken into consideration to do the comparison between spot procurement and supply chain procurement. The effectiveness of production capacity planning with considering of share rate up strategy was proved by using of the supply chain contract quantitatively.

Preconditions setting such as max trading volume, min trading volume and trading price are considered to improve the supply chain 
Citation: Wu S, Onari H (2016) Production Capacity Planning with Market Share Expansion under Different Procurement Strategies. Int J Econ Manag Sci 5: 345. doi:10.4172/2162-6359.1000345

Page 6 of 6

efficiency. Tasks such as negotiation process improvement, different desired share rate setting with different market situation are to be discussed in our future studies.

\section{References}

1. Karl I, Peter K (2010) Capacity reservation under spot market price uncertainty. Int J Production Economics 133: 272-279.

2. Mingzhou J, David W (2007) Capacity reservation contracts for high-tech industry. European Journal of Operational Research 176: 1659-1677.

3. JunWu, Wuyi Y, Yoshitsugu Y (2006) Risk analysis of a pay to delay capacity reservation contract. Optimization Methods and Software 21: 635-651.

4. Deng SM, Yano CA (2002) On the role of a second purchase opportunity in a two-echelon supply chain. Working paper, Department of Industrial Engineering and Operations Research, University of California, Berkeley, USA.

5. Jan AVM (1999) Coordinating investment, production and subcontracting. Management Science 4: 954- 971.

6. Po-yuan C (2011) The investment strtegies for a dynamic supply chain under stochastic demands. Int J Production economics 139: 80-89.

7. Jeffrey LC, Bharat S (1995) Risk aversion, generalized correlation and investment in manufacturing capacities. Journal of Operations Management 12: $225-237$.

8. Paolo R, Pierluigi A (2012) Capacity investment decision in co-opetitive network by information sharing. Computer \& Industrial Engineering 62: 359-367.
9. Adolfo CM, Carol B (2006) A decision support system for evaluating operations investment in high-technology business. Decision Support Systems 41 : 472-487.

10. Yigal G, Yunzeng W (2004) Revenue-sharing vs. wholesale-price contracts in assembly systems with random demand. Production and Operations Management 12: 23-33.

11. Avijit B (2005) Concurrent pricing and lot sizing for make-to-order contract production. Int J Production Economic 93-94: 189-195.

12. Jishnu H, Mahadevan B (2009) A procurement model using capacity reservation. European Journal of Operational Research 193: 303-316.

13. Puneet PM, Janat S (2008) Supply chain contracts with capacity investment decision: Two-way penalties for coordination. Int J Production Economics 114: 56-70.

14. Gerard PC, Martin AL (2001) Contracting to assure supply: How to share demand forecasts in a supply chain. Management Science 47: 629-646.

15. Mika O, Jukka H (2006) Investment decision-making in supplier networks: Managment of risk. International Journal of Production Economics 104: 201-213.

16. Fine $\mathrm{CH}$, Freund RM (1990) Optimal investment in product-flexible manufacturing capacity. Management Science 36: 449-466.

17. Agrawal V, Seshadri S (2000) Impact of uncertainty and risk-averse on price and order quantity in the newsvendor problem. Manufacturing and Service Operations Management 2: 410-423. 